\title{
Research of the trigger effect in diode-thyristor circuits of contactless relay devices
}

\author{
Erkin Abduraimov ${ }^{1}$ \\ ${ }^{1}$ Tashkent State Technical University named after Islam Karimov, Department of "Electrical Engineering" \\ of the Electrical Energy Faculty, Tashkent, University St. 2A, 100095, Uzbekistan
}

\begin{abstract}
The paper investigates the main properties of the trigger effect in diode-thyristor circuits and proposes the creation of small-sized thyristor contactless voltage relays, combining in one device a sensitive system to changes in input voltage and powerful actuators capable of switching large load currents. The article also discusses a non-contact thyristor relay of alternating current voltage, the load mode of which is analyzed, taking into account the voltage of the transition to the open state of the thyristor and the formula for the effective value of the voltage across the load. It is proposed to use the developed such relays as contactless switching and control equipment, which allow to reliably and quickly control the operating modes of electrical equipment, regulate the reactive power of capacitor banks, create ring networks, improve the quality of electricity in distribution networks and reduce capital costs for the construction of a power supply system.
\end{abstract}

\section{Introduction}

Currently, a set of technical solutions aimed at improving the efficiency and quality of automation devices, radio engineering, telecommunications, industrial and consumer electronics, requires widespread use and a deeper study of semiconductor circuits is of great practical importance to identify new possibilities for the practical application of semiconductor elements.

\subsection{Half-wave circuit}

The phenomenon of a sharp change in the current in the circuit with a slight change in the voltage at the input is called the trigger effect [1]. Let us consider the trigger effect, or in other words, the relay effect in the diodethyristor circuit using the example of a circuit when the thyristor VT is connected in series to the network through $\mathrm{R}_{\text {load }}$ active resistance, and current is supplied to the control circuit from the network through the active resistance $R_{\text {control }}$ and the diode VD (Fig.1.a) [2,3].

If you slowly increase the value of the input voltage, then at a certain value of $U_{\text {in, }}$, the amplitude value of the control signal will be equal to the thyristor opening current, at this moment the thyristor VT opens abruptly at an angle $\alpha=90^{\circ}$ (Fig. 1b). A further increase in the voltage leads to a decrease in the angle $\alpha$ almost to zero, i.e. the thyristor will carry the full positive half-wave of current. The voltage value at which the thyristor opens abruptly depends on the value of the parameters $R_{\text {con. }}$ and $\mathrm{R}_{\text {load }}$ Thus, the opening of the thyristor abruptly or the phenomenon of a sharp change in voltage or current across the load in the considered circuit can be called a trigger effect. An experimental study of the operating mode of a non-contact thyristor voltage relay was carried out according to the scheme shown in Fig. 1. [4,5]. In the study in the circuit, the resistance $\mathrm{R}_{\text {load }}=820 \mathrm{Ohm}$ was used as a load; diode - VD -226B; thyristor - VT KU201L and as a resistor $\mathrm{R}_{\text {control }}$ in the thyristor control circuit a variable resistance of $0 \div 25 \mathrm{kOhm}$ is used.

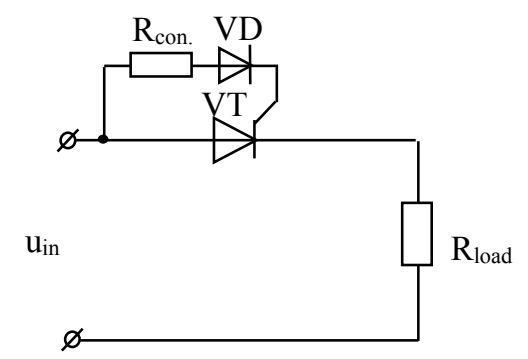

a)

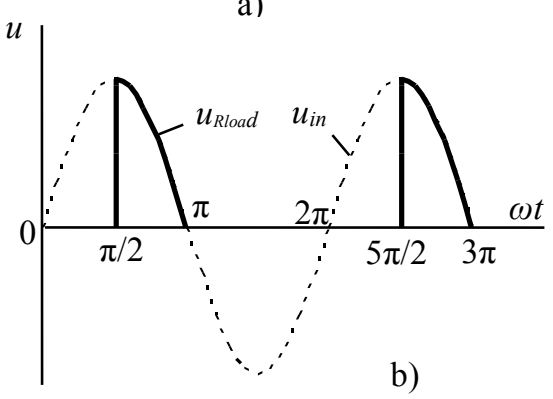

Fig. 1. a) Thyristor switching circuit b) Mains voltage and load wave forms 
Were removed the following dependencies $\mathrm{U}_{\text {load }}=f\left(\mathrm{I}_{\text {con. }}\right)$ at constant $\mathrm{U}_{\text {in }} ; \mathrm{I}_{\text {load }}=f\left(\mathrm{U}_{\text {in }}\right)$ at constant control current $\mathrm{I}_{\text {con.; }} \mathrm{U}_{\text {switch }}=f\left(\mathrm{R}_{\text {con. }}\right)$ which are shown in Fig. 2,3,4. Oscillograms of the shape of the voltage curves across the load of the considered circuit are shown in Fig. 5.

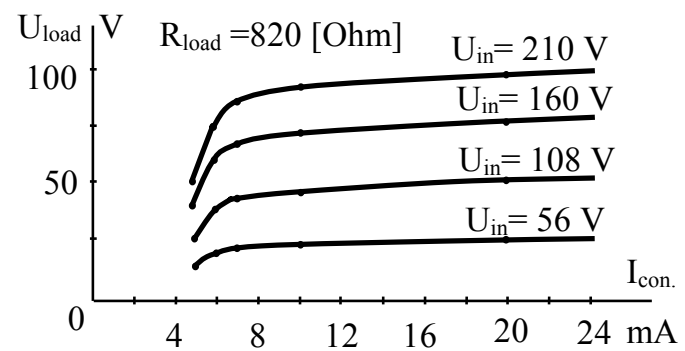

Fig. 2. Dependence $\mathrm{U}_{\mathrm{load}}=f\left(\mathrm{I}_{\mathrm{con}}\right)$ at various input voltages

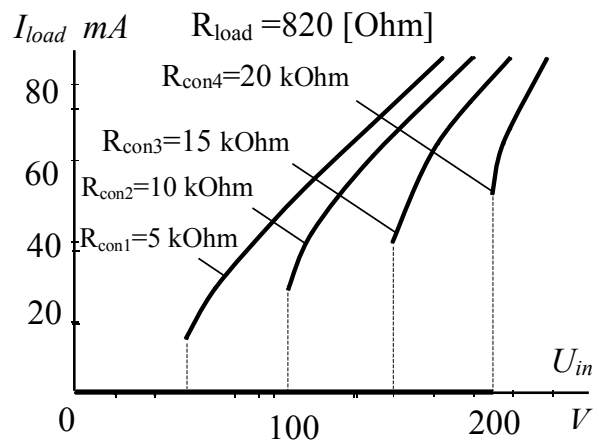

Fig. 3. Dependence $\mathrm{I}_{\mathrm{load}}=f\left(\mathrm{U}_{\mathrm{in}}\right)$ at different control currents

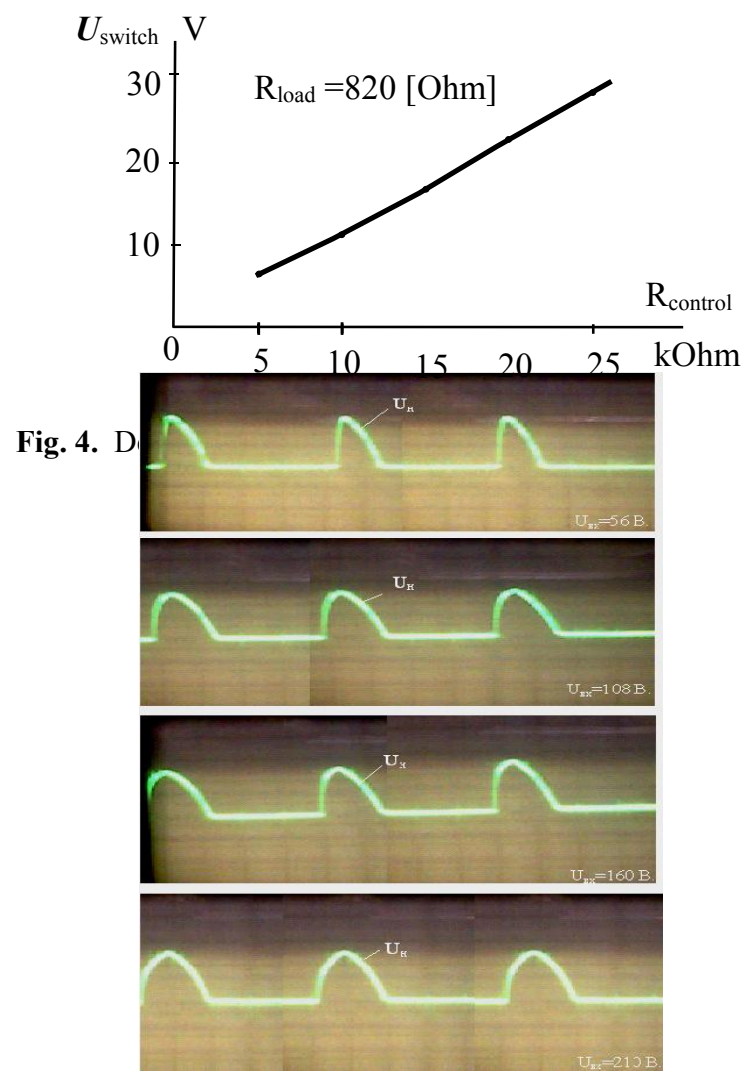

Fig. 5. Oscillogram of the voltage waveform at the load
In the absence of the controlling signal the thyristor is locked in both directions and is under the influence of source tension. When tension of a source reaches a certain value, the thyristor turns on in the moment of $\pi / 2$. At the same time tension on resistance will change a saltus to amplitude value of alternating voltage. Tension on the thyristor at the time of switching on changes a saltus almost to zero. Current duration via the thyristor and tension on resistance of loading makes a quarter of the period. A value of currents is determined by the following formulas In the absence of the controlling signal the thyristor is locked in both directions and is under the influence of source tension. When tension of a source reaches a certain value, the thyristor turns on in the moment of $\pi / 2$. At the same time tension on resistance will change a saltus to amplitude value of alternating voltage. Tension on the thyristor at the time of switching on changes a saltus almost to zero. Current duration via the thyristor and tension on resistance of loading makes a quarter of the period. [6,7]. A value of currents is determined by the following formula

$$
\begin{gathered}
i=\frac{U_{\text {in } \max }}{R} \operatorname{Sin} \omega t=I_{m} \operatorname{Sin} \omega t, \quad \alpha<\omega t<\pi \\
I=\frac{1}{2 \pi} \int_{\alpha}^{\pi} I_{m} \operatorname{Sin} \omega t d \omega t=\frac{1}{2 \pi} I_{m}(1+\operatorname{Cos} \alpha)
\end{gathered}
$$

In our situation at $\alpha=90^{\circ} \quad I=\frac{I_{m}}{2 \pi}$

The operating value of current:

$$
\begin{array}{r}
I=I_{m} \frac{1}{\sqrt{2 \pi}} \sqrt{\frac{1}{2}(\pi-\alpha)+\frac{1}{4} \operatorname{Sin} 2 \alpha} \\
\text { At } \alpha=90^{\circ} \quad \text { we will get } \quad I=\frac{I_{m}}{2 \sqrt{2}}
\end{array}
$$

\subsection{Full waive circuit}

The same trigger effect can be observed in the diodethyristor bridge circuit in Fig. 6. The circuit contains a VT thyristor connected to the diagonal of the diode bridge $\mathrm{VD}_{1}-\mathrm{VD}_{4}$ from the rectified current side. The bridge is connected in series with the load $\mathrm{R}_{\text {load }}$ to the AC voltage source. The current in the load circuit flows only when the thyristor in the diagonal of the diode bridge is open. When the signal at the control electrode of the thyristor is not sufficient, the thyristor is closed, so no current flows through the load. Upon reaching a certain value of the control signal, the thyristor will open at an angle of $90^{\circ}$ and will remain in the conducting state during the rest of the half-cycle of the alternating voltage. When the polarity of the mains voltage changes, a signal will be sent to the control electrode of the thyristor, which coincides with the polarity of the current flowing through the bridge and the thyristor will open at the same voltage value as with a positive half-wave of the supply mains. In this case, a current will flow through the load with an angle of inclusion $\pi / 2$ in both 
directions (Fig. 6.b). The first half of the current halfwave passes through the circuit: diode $\mathrm{VD}_{1}$, thyristor $\mathrm{VT}$, diode $\mathrm{VD}_{3}$, load $\mathrm{R}_{\text {load; }}$ the second half of the halfwave - along the circuit: load $\mathrm{R}_{\text {load}}$, diode $\mathrm{VD}_{2}$, thyristor VT and diode $\mathrm{VD}_{4}$. The supply voltage, minus the voltage drop across the diodes and thyristor, connected in the forward direction, is applied to the load $\mathrm{R}_{\text {load. }}$ When the mains voltage is below the voltage $U_{\text {switch }}$ or $\mathrm{I}_{\text {con. }}<\mathrm{I}_{\text {con. min }}$, the control signal is not sufficient to open the thyristor and the thyristor at the end of the next halfcycle, when the anode voltage drops to zero, closes and the load is disconnected from the power source. The thyristor switching voltage depends on the value of the control current. The value of the latter can be adjusted using the resistor parameter $\mathrm{R}_{\text {con. }}$.
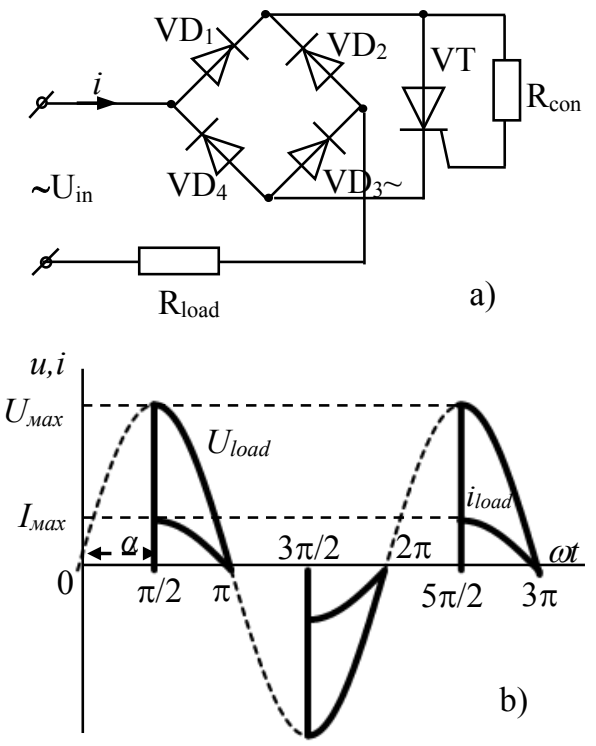

Fig. 6. a) Diode-thyristor bridge circuit; b) Voltage and load current waveforms

Thus, in the considered diode-thyristor circuits, a trigger effect is observed, which can be used to create contactless relay devices [8,9].

Experimental studies of the operating modes of the thyristor voltage relay were carried out according to the scheme shown in Fig. 6. The circuit used: thyristor KU $202 \mathrm{~K}$, diodes $\mathrm{D} 226 \mathrm{~B}$, resistance $\mathrm{R}_{\mathrm{H}}=770 \mathrm{Ohm}$ and $\mathrm{R}_{\mathrm{y}}$ $=10 \mathrm{kOhm}$.

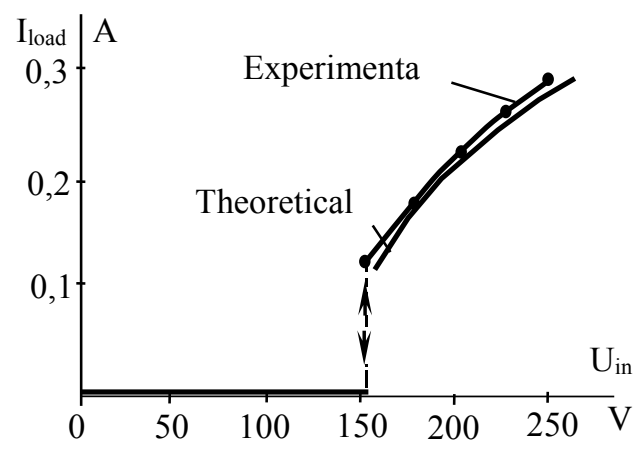

Fig. 7. Ampere-voltage characteristic
Figure 7 the current-voltage characteristic of the considered circuit is presented for $\mathrm{R}_{\mathrm{y}}=42 \mathrm{kOhm}$. The dependence of the change in the turn-on angle of the thyristor on the value of the input voltage is shown in Fig. 8.

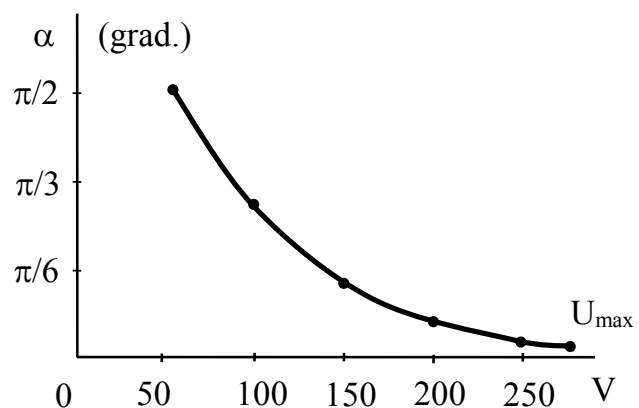

Fig. 8. Characteristic $\alpha=f\left(\mathrm{U}_{\max }\right)$

Figure 9 the obtained oscillograms of the shape of the current curves at the load are shown when the effective values of the mains voltage were: $U_{\text {in }}=40 \mathrm{~V} ; \mathrm{U}_{\text {in }}=70 \mathrm{~V}$; $\mathrm{U}_{\text {in }}=200 \mathrm{~V}$.
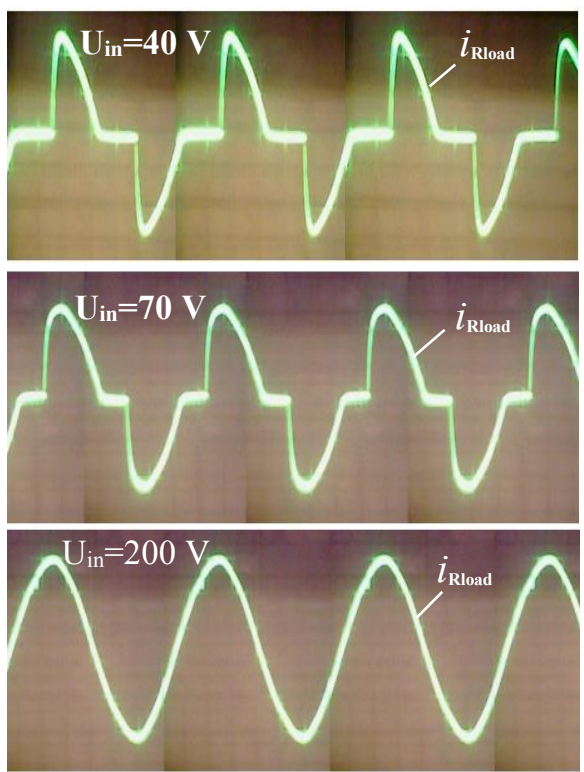

Fig. 9. Oscillograms forms of the current curve at the load

If we do not take into account the turn-on time and the forward voltage drop across the valves, then the instantaneous value of the load current is determined for the open state of the thyristor according to the following formula:

$$
i=\frac{U_{\mathrm{m}}}{R} \sin (\omega t+\alpha)
$$

where is the turn-on angle of the thyristor. The average and effective values of the load voltage are determined by the following formulas:

$$
U_{\text {mid }}=\frac{U_{\text {load }}}{\pi}(1+\cos \alpha)
$$




$$
U_{\text {load }}=\frac{U_{\max }}{\sqrt{2 \pi}} \sqrt{\pi-\alpha+\frac{\sin 2 \alpha}{2}}
$$

The relay is switched on at a certain mains voltage when $I_{\text {con. }}=\frac{U}{R_{\text {con. }}+R_{\text {load }}}>I_{\text {con.min }}$. Thus, by selecting the

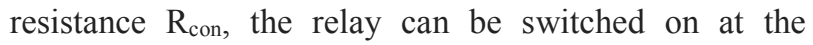
required mains voltage.

To determine the turn-on angle of the thyristor, it is necessary to know the turn-on voltage $\mathrm{U}_{\mathrm{in}}$, corresponding to the inflection point of the current-voltage characteristic of the thyristor.

Considering that

$$
u=U_{m} \sin (\omega t+\alpha)
$$

the turn-on angle of the thyristor occurs at $\alpha=90^{\circ}$. If $U_{m}>u_{\text {switch }}$. The thyristor does not go to the unlocked state if $U_{m}<U_{\text {switch. }}$

From the oscillogram you can see when the input voltage rises from zero to a certain value, the thyristor opens with a $90^{\circ}$ turn-on angle and the voltage across the load is a quarter of the period of the source voltage. A further increase in the applied voltage leads to an increase in the thyristor switching angle. The considered circuit supplies the load with both half-cycles of the alternating current. Thus, the load mode of operation of the considered circuit of the contactless voltage relay can be analyzed, taking into account the voltage of the transition to the open state of the thyristor, using formulas for the effective value of the voltage across the load. In this case, the opening angle of the thyristor is determined knowing the value of the thyristor turn-on voltage. $[10,13]$.

\section{Conclusion}

Thus, the theoretical and experimental studies of diodethyristor circuits have shown that a trigger or relay effect occurs in such circuits, and this can be used to create contactless voltage relays that combine in one device a sensitive system to changes in input voltage and powerful actuators capable of switching high load currents. The use of such relays, as contactless switching and control equipment, allows reliable and fast control of the operating modes of electrical equipment. $[11,12]$.

\section{References}

1. P. N. Matkhanov "Basis analysis of electric chains", the Higher school, M., 1977, p. 271.

2. Kadyrov T. M., Usmanov E. G., Abduraimov E.Kh. Use of numerical and graphic methods of the analysis nonlinear resistive chains. Materials of the AllRussian scientific conference "Innovative technologies in management, education, industry" ASINTEH-2007, - Russia,"Astrakhan university", 2007. Part 2- p.25 - 29.

3. Hoshimov, F.A., Bakhadirov, I.I., Erejepov, M., Djumamuratov, B. (2019) Development of method for normalizing electricity consumption E3S Web Conf 139 doi:10.1051/e3sconf/201913901074

4. AbduraimovE.Kh., Halmanov D.Kh. Theoretical analysis of semiconductor circuits. Eurasian Union of Scientists No. 3, 2019 Russia, pp. 60-63.

5. AbduraimovE.Kh. Khamidova N.E. Analysis of nonlinear resistive circuits. Theory and practice of modern science. XX International Scientific and Practical Conference. Moscow 2017 p. 62-64.

6. E. G. Usmanov, E. Kh. .Abduraimov, R.Ch. Karimov, the Nonlinear dynamic chain with a tiristor // Problems of informatics and power of the Republic of Uzbekistan, Tashkent, 2006 №. 2,3. p. 37-41

7. Abduraimov E.Kh., Halmanov D.Kh. Development of a non-contact optoelectronic switching device. - Problems of energy and resource conservation, TSTU. - Tashkent, 2018, -№ 3-4 pp. 145-149.

8. Bobojanov M.K., Usmanov E.G., AbduraimovE.Kh., Karimov R.Ch. Resistive time delay swishes Seintifie journal "European Science Review" Austria, Vienna, 2018 -№1-2 210-212c PP210-212 (05.00.00; №3)

9. Abduraimov E.Kh. -Optoelectronic contactless switching devices. Bulletin of Tashkent State Technical University No. 3, 2016, pp. 73-78.

10. Usmanov E.G., Abduraimov E.Kh. - Contactless timers. - Problems of energy and resource conservation, TSTU. - Tashkent, 2016, No. 3-4 - pp. 84-87.

11. Abduraimov E.Kh., Khushiev S.M. Analysis of the load mode of a non-contact thyristor voltage relay. Bulletin of Tashkent State Technical University No. 4, 2007 p. $35-38$

12. Usmanov E.G, Abduraimov E. Kh, Halmanov D.Kh, Karimov R.Ch. Optoelectronic reloading with highspeed. Republic of Uzbekistan. Official Bulletin of the Intellectual Property Agency, - Tashkent, 2018, No. 11 (211) - S.29.

13. Abduraimov E. Kh., Khalmanov D.Kh., B.A.Nurmatov, S.A. Dusmukhamedova, Khamidova N.E. Theoretical research and development optoelectronic communication devices. Journal of Physics: Conference Series (JPCS) for further publishing.Conf.Series 1515022055 (2020) 